\title{
MULHER E A PSIQUIATRIA NO SÉCULO XIX
}

\author{
Adriana do Val Alves Taveira ${ }^{1}$ \\ Juliana Rodrigues ${ }^{2}$ \\ Daisa Maria Levandoski ${ }^{3}$
}

\begin{abstract}
RESUMO: A partir de estudos sobre as formas de poder estruturado no Estado Moderno, controlador de alguns grupos da sociedade é que o presente artigo foi concebido. A pesquisa originária deste artigo aborda a construção dos saberes psiquiátricos sobre o corpo feminino e como este processo definiu espaços para as mulheres no século XIX. Neste contexto, o organismo da mulher visto das mais diferentes maneiras, passa a ser estudado pela medicina principalmente pela área psiquiátrica. Duas obras de grande contribuição histórico-filosóficas foram primordiais para o presente estudo. Em primeiro lugar, a obra História das mulheres no Brasil, organizado por Mary Del Priore e, em segundo, História da sexualidade I e II, de Foucault. A partir da análise sobre essas e outras indicadas nas Referências deste trabalho, constatou-se vários dados que demonstram a sujeição da mulher aos limites de sua sexualidade, tais conhecimentos ainda refletem nos dias de hoje como ideias construídas e fixadas como verdades ao longo dos anos. $O$ objetivo da pesquisa consiste na discussão de tais influências buscando assim entender as relações de gênero ainda demarcadas na sociedade atual, que se utiliza desse dispositivo biológico como condição de dominação social e opressão.
\end{abstract}

Palavras-Chave: Subjetividade; Psiquiatria; Corpo feminino.

\section{WOMAN AND PSYCHIATRY IN THE XIX CENTURY}

\begin{abstract}
From the studies of the work History of women in Brazil, organized by Mary Del Priore, is that the present article was conceived. The research originated in this article approaches the construction of psychiatric knowledge about the female body and how this process defined spaces for women in the nineteenth century. In this context, the woman's organism seen in the most different ways, starts to be studied by medicine mainly in the psychiatric area. These studies report data that subject women to the limits of their sexuality, such knowledge still reflects today as ideas built and fixed as truths over the years. The objective of the research is to discuss such influences in order to understand the gender relations still demarcated in the current society, which uses this biological device as a condition of social domination and oppression.
\end{abstract}

Keywords: Subjectivity; Psychiatry; Femininebody.

\section{Introdução}

O presente artigo busca fazer uma reflexão a respeito da construção dos saberes psiquiátricos sobre o corpo feminino e como este processo definiu espaços para as mulheres no século XIX, com repercussões até os dias atuais.

Utilizou-se em sua elaboração uma metodologia indutivo-sistemática, realizada por meio de uma pesquisa exploratória sobre o referencial bibliográfico apontado no último item do trabalho. Lembra-se que segundo Lakatos e Marconi (1991), “a pesquisa bibliográfica tem por

\footnotetext{
${ }^{1}$ Pós-doutorado pela Universidade de Coimbra-Pt em "Democracia e Direitos Humanos", Doutora em Direito pela Universidade Estadual Paulista - UNESP - Professora Associada da Universidade Estadual do Oeste do Paraná UNIOESTE. Líder do Grupo de Estudo e Pesquisa de Gênero e Empoderamento da Mulher - GEPGEM. E-mail: adriana_val_taveira@hotmail.com

${ }^{2}$ Mestre em Educação pela Universidade Estadual do Oeste do Paraná-UNIOESTE, Especialista em Docência do Ensino Superior pela Universidade Norte do Paraná-UNOPAR. Professora da rede básica de ensino Francisco Beltrão. E-mail: motta.julianarodrigues@gmail.com

${ }^{3}$ Graduada em Psicologia pela Faculdade de Pato Branco - FADEP, em 2016. Membro do Grupo de Estudo e Pesquisa de Gênero e Empoderamento da Mulher-GEPGEM. E-mail: adriana_val_taveira@hotmail.com
} 
objetivo colocar o pesquisador em contato direto com tudo o que foi escrito, dito ou filmado sobre determinado assunto".

No primeiro tópico analisou-se o papel da psiquiatria no século XIX em torno de suas conquistas no estudo do corpo feminino, objetivando compreender seus limites a partir da posição de "objeto a ser observado" dentro do qual a mulher foi inserida no século XIX, como um personagem a ser controlado e afinado aos padrões indicadores de normalidade da sociedade burguesa.

A fim de melhor compreensão sobre a estrutura de poder construído a partir do século XVII, analisou-se, no segundo tópico, as contribuições de Foucault sobre a estrutura do Biopoder, conceito elaborado pelo autor e que contribui para o entendimento dos fenômenos sociais opressores sobre vários sujeitos sociais, inclusive sobre a mulher.

A seguir, no tópico "a visão da psiquiatria sobre o corpo feminino no século XIX" foi analisada a forma de construção do pensamento psiquiátrico em torno da mulher, cuja loucura apoiava, em regra, seus diagnósticos em torno da natureza e sexualidade da mulher.

Logo após, discute-se a psiquiatria como dispositivo de poder/saber sobre o corpo feminino, esta análise remete aos conhecimentos elaborados pela ciência psiquiatra sobre a mulher, evidenciando como esse processo de saber foi utilizado para a subjetividade, e como o diagnóstico foi necessário para identificar a normalidade do comportamento desse sexo. Trás também a concepção de dispositivo de poder elaborada por Foucault entrecruzando ao saber psiquiátrico para subjetivação da mulher.

Por fim, a conclusão do trabalho e seus referenciais que permitem apontamentos quanto à proposição inicial da pesquisa, ou seja, a visão da psiquiatria no século XIX, as relações de gênero ainda demarcado na sociedade atual e os dispositivos biológicos como condição de dominação social e opressão sobre a mulher.

\section{A Psiquiatria no Século XIX}

O século XIX foi marcado, principalmente no continente europeu, por grandes transformações a partir da revolução industrial e dos ideais burgueses do Estado moderno, gerando consistentes alterações em outros sistemas como nas relações de trabalho humano, na medicina e demais relações sociais, mudanças que se disseminaram para o novo mundo, inclusive para o Brasil.

Com o fim do Império no território nacional e o advento da República brasileira anunciou-se o começo de um tempo marcado pelo redimensionamento das políticas de controle social, com a rigidez e parâmetros próprios dos ideais burgueses definidores da família, da nova 
ordem nas cidades e do papel da mulher dentro desse contexto.

Conforme expõe Magali Engel (2004, p.270), com os grandes estudiosos na área da psicanálise e medicina psiquiatra "consolidava-se o processo de medicalização da loucura, transformando-a em doença mental, em objeto exclusivo de um saber e de uma prática especializados, monopolizados pelo alienista", não sendo diferente no Brasil, o que se comprova com a criação da primeira instituição exclusivamente destinada a recolher alienados mentais, o Hospício de Pedro II, e com a inserção da cadeira de Clínica Psiquiátrica nos cursos de medicina do Império, em 1879.

Evidente ficou o comprometimento da psiquiatria com as políticas de controle social propostas pelas primeiras administrações republicanas, o universo temático privilegiado pelos especialistas brasileiros na construção da loucura como doença mental deixa entrever as principais áreas de intervenção das estratégias normatizadoras, ou seja, os comportamentos sexuais, as relações de trabalho, a segurança pública, as condutas individuais e as manifestações coletivas de caráter religioso, social e político, e, dentro dessa perspectiva psiquiatra, subsume-se a sexualidade feminina.

Presenciamos ainda nesse período o nascimento de uma nova mulher nas relações da chamada família burguesa, agora marcada pela valorização da intimidade e da maternidade. Um sólido ambiente familiar, o lar acolhedor, filhos educados e esposa dedicada ao marido, às crianças e desobrigada de qualquer trabalho produtivo representavam o ideal de retidão e probidade, um tesouro social imprescindível. Verdadeiros emblemas desse mundo relativamente fechado, a boa reputação financeira e a articulação com a parentela como forma de proteção ao mundo externo também marcaram o processo de urbanização do país (D'Incao, 2004).

Os estudos relativos à psiquiatria feminina que indicavam anomalias mentais restringiamse às denominadas "regras mensais" causadoras de transtornos de "histeria" desde a menarca até a menopausa. Aos comportamentos fora dos padrões indicados pela sociedade burguesa como infidelidade, multiplicidade de parceiros sexuais, comportamento relapso em relação ao marido ou aos filhos foram considerados, pela nova ciência que despontava, como diagnósticos de anomalia.

Conforme será analisado, deve-se observar que, a partir do século XVIII e XIX, desenvolveu-se na Europa, no bojo da constituição do biopoder, a ideia de que a mulher teria seu destino atrelado ao casamento e à maternidade, teorias construídas a partir da preocupação política com a produção da vida e a qualidade da população, que passa a inserir a mulher e a maternidade como objetos privilegiados de intervenção e controle.

Biopoder, segundo Michel Foucault, consistia em um conjunto de práticas e discursos que instituem a sociedade burguesa e a organizam; $\mathrm{O}$ autor dividiu o objeto de sua análise em fases: 
Em uma fase inicial, o corpo e a espécie passam a ser considerados paralelos e a espécie humana passa a ser contabilizada, classificada, objeto de estimativas e pesquisas quantitativas. Os governos tornam-se crescentemente preocupados com a "população", seus fenômenos e variáveis próprias como a natalidade, a mortalidade, a esperança de vida e a incidência de doenças. (FOUCAULT, 1988, p. 79).

O tema sobre o biopoder será objeto de análise no item a seguir e sua abordagem busca o entendimento e compreensão da temática da inserção da mulher nos padrões convenientes da sociedade que se vinha estruturando a partir do "Estado Burguês".

Incontáveis foram os teóricos das mais diversas áreas do conhecimento a defenderem reformas sociais baseadas no controle médico da sociedade. Segundo expõe Miskolcio (2003), o desvio era visto a partir das características do homem considerado padrão por nossa sociedade, ou seja, o homem branco, heterossexual e burguês. Nessa perspectiva, a mulher, o proletariado, o homossexual estariam fora da normalidade, deveriam sofrer as corrigendas necessárias à sua adequação.

É imprescindível acrescentar a abordagem de Simone de Beauvoir a respeito da psicanálise de Sigmund Freud, cuja construção deu-se a partir do masculino, tratando a mulher com apenas alguns adendos em relação ao homem, segundo a autora

Freud não se preocupou muito com o destino da mulher; é claro que calcou a descrição do destino feminino sobre o masculino, restringindo-se a modificar alguns traços. Antes de Freud, o sexologista Marañon declarara: "Enquanto energia diferençada, a libido é, pode-se dizer, uma força de sentido viril. Diremos o mesmo do orgasmo". Na sua opinião, as mulheres que alcançam o orgasmo são mulheres "virilóides"; o impulso sexual tem uma "única direção" e a mulher encontra-se ainda no meio do caminho (1). Freud não vai tão longe; admite que a sexualidade da mulher é tão evoluída quanto a do homem; mas não a estuda, por assim dizer, em si mesma. Escreve: "A libido é de maneira constante e regular de essência masculina, surja ela no homem ou na mulher". (BEAUVOIR, 1980, p. 59).

A manutenção da histeria no território feminino foi reforçada ao longo dos séculos XVIII e XIX, fazendo parte da construção de uma determinada concepção da diferença entre os sexos articulada na modernidade, segundo a qual homens e mulheres seriam dotados de características físicas e morais diferentes e complementares (NUNES, 2010). Os discursos médicos procuravam delinear minuciosamente as diferenças entre os sexos, supondo também patologias diferentes. Assim, por exemplo, a histeria seria feminina, e a hipocondria, masculina.

Os apontamentos acima demonstram a posição de "objeto a ser observado" dentro do qual a mulher foi inserida no Século XIX, a fim de ser controlada e afinada aos padrões indicadores de normalidade da sociedade burguesa. 


\section{O Biopoder em Foucault}

Biopoder, fenômeno que, segundo Foucault $(1988,2000)$ consolidou-se no século XIX e tinha como um de seus paradigmas a "família canônica" da década de 1830, utilizando-a como um padrão a orientar os demais núcleos sociais, como mais uma forma de controle sócio-político e econômico da sociedade. Os indivíduos e suas famílias que não se encaixassem nos padrões economicamente produtivos passavam a serem vistos como aberrações. A família tornou-se o local privilegiado para a distinção entre o normal e o anormal, incluindo a sexualidade de seus membros, principalmente da mulher.

"A repressão ao sexo se sustenta em razão de uma grave caução histórica e política que o protege [...] o sexo é incompatível com a colocação no trabalho geral e intensa" (Foucault, 1988, p. 8), continuando o autor aponta que a idade da repressão se inicia no século XVII, que coincide com o desenvolvimento do capitalismo, ou seja, faz parte da ordem burguesa.

O autor expõe com muita clareza que alguns sujeitos da sociedade moderna foram alvo de controle, a fim de ser alcançados objetivos bem determinados por seus atores políticos, dentre esses sujeitos, a mulher foi inserida e submetida através de vários mecanismos de controle a um padrão aceitável e conveniente, cuja transgressão a sujeitaria a medidas psiquiatras e de isolamento, Foucault (1988) aponta como padrões a lhe ser conferidos como normalidade aceita: a natureza maternal, o cuidado com a família, com o companheiro e demais obrigações domésticas, além de lhe impor um "natural desinteresse pelo sexo".

Nesse mesmo sentido Soihet afirma:

As imposições da nova ordem tinham o respaldo da ciência, o paradigma do momento. A medicina social assegurava como características femininas, por razões biológicas: a fragilidade, o recato, o predomínio das faculdades afetivas sobre as intelectuais, a subordinação da sexualidade à vocação maternal. Em oposição, o homem conjugava à sua força física uma natureza autoritária, empreendedora, racional e uma sexualidade sem freios. As características atribuídas às mulheres eram suficientes para justificar que se exigisse delas uma atitude de submissão, um comportamento que não maculasse sua honra. Estavam impedidas do exercício da sexualidade antes de se casarem e, depois, deviam restringi-la ao âmbito desse casamento. Cesare Lombroso, médico italiano e nome conceituado da criminologia no final do século XIX, com base nesses pressupostos, argumentava que as leis contra o adultério só deveriam atingir a mulher não predisposta pela natureza para esse tipo de comportamento. Aquelas dotadas de erotismo intenso e forte inteligência, seriam despidas do sentimento de maternidade, característica inata da mulher normal, e consideradas extremamente perigosas. Constituíam-se nas criminosas natas, nas prostitutas e nas loucas que deveriam ser afastadas do convívio social (2004, p. 304).

Ao tentar dar a explicação para as manifestações de poder na modernidade, Foucault 
$(1988,2000)$ utiliza a expressão Biopoder, manifestação esta que, no seu entender, passou por duas acomodações, sendo a primeira por volta dos séculos XVII e XVIII denominada por ele como poder disciplinar e, a segunda, a partir de fins do século XVIII, com a biopolítica. O autor tem ciência de que não se trata simplesmente de dizer que um poder se sobrepõe ao outro historicamente, mas muito mais de se perceber e identificar que, a partir do século XVII, uma série de práticas atreladas a uma rede de saberes são construídas socialmente, o que pôde configurar o denominado "poder disciplinar".

Continuando, expõe que, mais tarde, já no fim do século XVIII, percebe-se o desenvolvimento de uma nova forma de poder, que ele denomina "biopolítica", que não põe fim ao poder disciplinar, pelo contrário, as duas formas de poderes passam a conviver simultaneamente, cada uma delas com suas práticas específicas e complementares.

A sua preocupação fundamental concentra-se na análise de duas proposições: por onde passa o poder, quais são suas práticas e como ele age. E complementando, nas palavras do autor, pretendeu-se "tornar visível o que precisamente é visível” (FOUCAULT, 1988, p.49).

O poder se dá por uma série de práticas que configuram as relações dos indivíduos entre si, entre as instituições e os indivíduos, entre os Estados em suas relações entre si; entre o Estado em suas relações com as instituições e com os indivíduos. Enfim,

[...]as relações de poder permeiam o tecido social e em cada seguimento da sociedade teremos práticas variadas de poder" que são históricas, localizadas, as quais podem estar ou não vinculadas ao Estado. "Os poderes se exercem em níveis variados e em pontos diferentes da rede social e neste complexo os micropoderes existem integrados ou não ao Estado" (FOUCAULT, 1988, p.58).

$\mathrm{Na}$ análise da primeira forma de acomodação do poder chamado por Foucault de poder disciplinar, percebe-se que é uma expressão do poder que se aplica basicamente aos indivíduos, ao ser humano enquanto corpo - o corpo como máquina -, uma anatomia do detalhe em que os corpos eram treinados para uma ação regrada, disciplinada. Esta tecnologia da disciplina se desenvolveu por uma rede de instituições como o exército, hospitais, igrejas, oficinas de trabalho, escolas e família. Como exemplo, pode-se citar a Revolução industrial em que havia a necessidade de se ter um corpo domesticado e ao mesmo tempo dócil, um corpo regrado economicamente e politicamente obediente (FOUCAULT, 1988).

Mas qual a relação da Teoria do Biopoder de Foucault e o presente trabalho, que aborda a questão da Mulher e a Psiquiatria no século XIX? Na verdade, o próprio autor, ora analisado dá essa resposta em sua obra "História da sexualidade I: A vontade de saber" (1988), em que o autor constata que os mecanismos de poder são historicamente construídos e através do saberespoderes de seu criador instituiu-se a ideia do controle do corpo, especialmente, o controle do 
corpo e da sexualidade da mulher, como um ponto central.

Emmerick (2007) afirma que, o controle do corpo e da sexualidade sempre se fez presente nos mais distintos momentos da história das sociedades. No entanto, citando Foucault, reafirma que o saber sobre corpo tornou-se poder sobre o corpo, cuja compreensão verifica-se a partir do denominado poder disciplinar. No que diz respeito ao controle do corpo e da sexualidade da mulher, o autor remonta à antiguidade. Contudo, é com o surgimento da Era Cristã, no decorrer da Idade Média e início da Idade Moderna que tal controle se intensifica, progressivamente. O corpo que até a Idade Média era sexuado passa a ser desvalorizado e reprimido, por meio de um sistema medieval dominado pelo pensamento simbólico (EMMERICK, 2007).

No contexto de uma sociedade em transformação, a partir da era moderna, em que as relações sociais tornavam-se mais complexas, foi preciso compreender o corpo e o sexo enquanto objetos de disciplina, de regulamentação, de controle social e de disputa política nas relações de poder. Relações essas construídas sob a ótica do masculino, com base na disciplina do corpo e regulação das populações, onde há, historicamente, uma submissão do corpo e da sexualidade do feminino.

Portanto, sob a ótica de Foucault, percebe-se a construção de um domínio e controle sobre alguns membros sociais, no caso, a mulher, a fim de inseri-la na esfera conveniente, segundo a intenção dos atores estruturadores da sociedade moderna, buscando a satisfação dos ideais burgueses.

\section{A Visão da Psiquiatria Sobre o Corpo Feminino no Século XIX}

Uma das imagens fortemente apropriadas e disseminadas pelo século XIX ocidental sobre a existência da mulher é sua associação à natureza, já o homem identificado à cultura. Práticas liberais, embora pautadas em um discurso de igualdade, negavam às mulheres o acesso à cidadania, justificando-se na diferença entre os sexos. Tal atitude ganha força a partir das descobertas da medicina e da biologia, que confirmavam cientificamente a dicotomia, em que homens eram comparados ao cérebro, inteligência, razão lúcida, capacidade de decisão. Já as mulheres, coração, sensibilidade e sentimentos.

Tais questões contribuíram para que a construção da imagem feminina fosse pautada a partir da natureza, qualificando a mulher como naturalmente frágil, bonita, sedutora, submissa, doce. Entretanto, muitas qualidades negativas como, por exemplo, a infidelidade e a amoralidade, também eram entendidas como atributos naturais da mulher, gerando assim uma visão profundamente ambígua do ser feminino.

A mulher transformava-se em ser moral e socialmente perigoso, devendo ser submetida a 
um conjunto de normas extremamente rígidas que assegurassem o cumprimento do seu papel social de esposa e mãe, garantindo a vitória do bem sobre o mal. Qualquer comportamento, apresentado por ela que se desviasse do esperado, a deixava como um ser antinatural, principalmente no que diz respeito à sexualidade e afetividade, eram vistos como estranhos à sua natureza.

Todas essas considerações levaram a construção da especificidade da mulher diante da loucura, o foco do diagnóstico voltava-se para a esfera da sua natureza e sexualidade. O homem era visto como portador de desvios relativos aos papéis sociais, tais como o de trabalhador, o de provedor etc, ou seja, os distúrbios mentais estariam relacionados ao desempenho desses papéis ou à recusa de incorporá-los. Para a mulher, sua fisiologia estaria ligada diretamente a predisposição à doença mental.

A menstruação, a gravidez e o parto seriam aspectos essencialmente priorizados na definição e no diagnóstico das enfermidades mentais femininas. O início e o fim do período menstrual eram considerados como momentos extremamente propícios à manifestação dos distúrbios mentais. Mais tarde um esboço da psiquiatria forense, Franco da Rocha adverte que as perturbações menstruais não teriam a real importância que as pessoas davam e que tudo não passava de coincidência.

Para além das inúmeras controvérsias acerca das características essenciais da histeria enquanto doença, o perfil da histérica era traçado de um modo mais ou menos consensual, sendo este, instável e imprevisível, marcado principalmente pelo desequilíbrio entre as "faculdades morais superiores, as paixões, instintos e desejos".

Uma visão desvinculada da relação exclusiva com o útero à histeria, visto como uma perturbação psíquica, afetando as funções afetivas e intelectuais, e restritas ao âmbito das manifestações degenerativas, o mal histérico poderia atingir as crianças e os velhos de ambos os sexos e os homens adultos, a primeira vista, livrando um pouco a responsabilidade da mulher a respeito da loucura.

Porém, a construção do perfil do homem histérico tem ênfase como produto da herança materna, bem como pela atribuição de traços femininos ao homem, o que chamavam de traços característicos da natureza feminina, serem extremamente suscetíveis e volúveis, vivamente impressionáveis e excessivamente vaidosos e caprichosos. Reafirmando e vivendo uma frase dita pelo psiquiatra francês Ulysse Trélat onde defendia que "toda mulher é feita para sentir, e sentir é quase histeria".

\section{A Psiquiatria como Dispositivo de Poder sobre o Corpo Feminino}


Para prosseguir a discussão é necessário primeiramente compreender o que se quer dizer com dispositivo de poder a partir da perspectiva Foucaultiana, para Foucault (2000) um dispositivo de poder é:

um conjunto decididamente heterogêneo que engloba discursos, instituições, organizações arquitetônicas, decisões regulamentares, leis, medidas administrativas, enunciados científicos, proposições filosóficas, morais, filantrópicas. Em suma, o dito e o não dito são os elementos do dispositivo. $\mathrm{O}$ dispositivo é a rede que se pode tecer entre estes elementos (Foucault, 2000, p. 244).

Desta forma, utiliza-se o conceito de dispositivo de poder porque melhor dialoga com as práticas sobre o corpo feminino no século XIX. O saber elaborado sobre o corpo serviu entre outras funções como aparato de dominação física, social, cultural e biológica. Já o conceito de poder elaborado por ele, desmistifica o pensamento de que o poder está centralizado em uma instituição, ou num determinado sujeito, mas sim, tem em Foucault um sentido que reprime, e por outro lado produz saberes e verdades, neste sentido o poder nem sempre é algo ruim, mas uma relação de construção de saberes, ou:

Uma técnica que é centrada no corpo, produz efeitos individualizantes, manipula o corpo como foco de forças que é preciso tornar úteis e dóceis ao mesmo tempo. E, de outro lado, temos uma tecnologia que, por sua vez, é centrada não no corpo, mas na vida; uma tecnologia que agrupa os efeitos de massas próprios de uma população (FOUCAULT, 1999, p.297).

É o que se constitui e se constituiu como verdade para o corpo, nesse caso especificamente para o que é ser mulher como condição e resultado de seu corpo feminino. $\mathrm{O}$ poder aqui está na ciência psiquiátrica. O corpo feminino foi por muito tempo estudado nas mais diferentes áreas científicas, mas nenhuma caracterizou tanto uma subjetividade biológica como a psiquiatria. Já que, era a ciência que explicava quase tudo sobre o ser humano nesse período. Até meados do século XIX todo o cotidiano feminino era administrado pelos interesses masculinos e a psiquiatria serviu de verdade absoluta, apropriação e dominação masculina, visto que, caracterizava e discutia o corpo da mulher como inferior ao do homem.

Todas as questões a que se detinham eram ligadas ao ciclo menstrual, as mulheres eram entendidas como loucas, histéricas, isoladas e internadas em hospitais psiquiátricos, isso tudo alicerçado no saber de que a menstruação deixava muitas mulheres insanas. Este saber contribuiu significativamente para dominação tanto cultural como social, pois a mulher possuía um defeito físico, que justificava suas doenças mentais, e esse defeito físico não atingia o ser homem. As mulheres sangravam mensalmente, e isso fazia com que muitas perdessem o juízo.

Conforme Engel (1997); 
[...] durante a infância, teve suas "primeiras manifestações histéricas e epilépticas" aos 14 anos, quando menstruou pela primeira vez. A partir dos 21 anos, depois de ter se casado, apresentou "sensíveis melhoras do estado psicopático", revelando "extrema dedicação ao marido", ao qual, contudo, repudiaria mais tarde, abandonando o "lar doméstico" e entregando-se "sucessivamente a três homens de baixa classe". O médico fez questão de sublinhar: "Esta infidelidade conjugal manifestava-se alguns dias antes do período catamenial. [...] Seus corrimentos mensais desde os primeiros, muito abundantes e acompanhados de grande excitação". Nos três primeiros dias posteriores à internação, M. J. apresentava-se aos olhos do médico "muito loquaz, exaltada", relatando "em linguagem demasiado livre, os seus amores e lamentando a ausência do último amante". M. J. não aceitou passivamente a sua reclusão e, em duas cartas enviadas ao marido, exigia a sua liberdade e denunciava as condições do estabelecimento no qual estava internada. Além disso, a punição representada pela internação não foi suficiente para que ela mudasse seu comportamento. Continuando a dar livre vazão a seus sentimentos e desejos, lançava "olhares libidinosos", fazia "sinais convencionais" e escrevia "cartas a um doente que [via] ao longe, durante os passeios, pelo jardim do estabelecimento", o que lhe valeria o rótulo de "ninfomaníaca", anotado em sua ficha de observação (ENGEL, 1997, p.63).

Como se observa para a mulher só havia um caminho, ela era sempre uma possível vítima de seu próprio sistema biológico, e sua salvação estava no casamento. As concepções sobre o corpo feminino também acompanham as modificações sociais, políticas e econômicas. Assim, podemos afirmar que o corpo e a subjetividade são construídos historicamente, ou seja, cada sociedade tem seu modelo de corpo, tem seus saberes sobre o corpo, e cada época tem seu modo particular de representá-lo.

A representação desse corpo se dá a partir da cultura, embora possamos definir cultura de várias formas, ela apresenta diferentes modos de organização da vida social, de indivíduos e grupos sociais. Portanto, é a maneira como os indivíduos expressam suas crenças e seus saberes em um determinado período.

Segundo Foucault (1994) a relação entre mulher e loucura é complexa, e leva a pensar na situação social das mulheres como esposas, filhas e mães, no século XIX desenvolveu-se um saber a respeito da sexualidade. Assim, sabia-se o que era e como deveria ser a relação dentro do casamento, este saber contou também com o dispositivo religioso que adentrava as casas para instituir a moralidade, desta forma o casamento era meramente para reprodução. Ao contrário da sexualidade permitida, era a considerada ilícita e perigosa, tanto para saúde física ou mental.

A ideia que permeia este saber é de que; a mulher apontada como normal e puritana era a esposa e mãe, a mulher que fugisse a estas regras sociais era a prostituta, o homem poderia pecar com a prostituta, já que, mantinha um casamento dentro das morais sociais, mas sua relação com a esposa era puramente reprodutiva e dentro do que a religião permitia. A insatisfação feminina é compreensível nesse sentido, seu próprio corpo lhe foi negado, sua sexualidade reprimida. 
Ainda segundo Foucault ${ }^{4}$ no século XIX ocorria a histerização da mulher, isto porque ela estava condicionada de maneira diferente diante de seu próprio corpo comparada ao homem, presa a sua condição reprodutora. As fases da vida da mulher como puberdade, gravidez e menopausa, eram caracterizadas como desequilíbrios emocionais. Por toda a vida, a mulher seria um ser propício a perturbações mentais, tendo destaque especial como já mencionamos a menstruação.

Desta forma, a sociedade agia sobre o problema da loucura feminina, a partir de saberes inconclusos, saberes que compunham um diagnóstico. Dentro dessas limitações sociais o que não caracterizava-se como normal, logo era considerado loucura, e a maneira de justificar a construção desses sintomas de loucura era explicitamente o corpo feminino e seus movimentos biológicos, que eram desconhecidos, mas julgava-se saber o suficiente para transformar mulheres e pessoas indesejadas na sociedade, em loucas.

Segundo Engel (1997);

\begin{abstract}
Não foi por acaso que os primeiros tempos republicanos assinalaram as vitórias mais expressivas dos psiquiatras brasileiros na busca obsessiva de conquistarem para si o monopólio da única verdade possível sobre a loucura e, portanto, controlar todos aqueles que pudessem ser capturados nas malhas cada vez mais extensas e emaranhadas da doença mental. Evidenciando o comprometimento da psiquiatria com as políticas de controle social propostas pelas primeiras administrações republicanas, o universo temático privilegiado pelos especialistas brasileiros na construção da loucura como doença mental deixa entrever as principais áreas de intervenção das estratégias normatizadoras: os comportamentos sexuais, as relações de trabalho, a segurança pública, as condutas individuais e as manifestações coletivas de caráter religioso, social, político etc (ENGEL, 1997, p.71).
\end{abstract}

Sem dúvida os saberes elaborados dentro de uma sociedade mostram como ela se define, quem ela inclui e quem exclui servindo de aparelho de controle político, social e sexual. Assim, a pergunta de Foucault é essencial para pensar a posição da mulher hoje: Em que medida um dispositivo de poder pode ser produtor de um certo número de enunciados, de discursos, e, em consequência de todas as formas de representação que podem surgir dali?

Esta pergunta não é difícil de responder, basta observar a organização de nossa sociedade, as lutas femininas por direitos iguais, essas lutas demonstram que os mesmos saberes do século XIX ainda interferem em discursos atuais, saberes que por exemplo, condicionam a mulher a um estado de maturidade que antecede ao do homem, não é possível comprovar esse saber como verdade, mas ele está anunciado na sociedade como verdade, como saber biológico e serve de aparato de diferença. Isso não significa que trará benefícios ao corpo feminino, pelo contrário, é um saber que aprisiona o corpo e lhe sugestiona um amadurecimento que não existe. 
O que existe é responsabilidades diferentes entre ambos os sexos, e seguidamente cobram mais da mulher uma racionalidade para perdoar, para amar e se colocar no lugar do outro, tornam o corpo feminino dócil para compreender sua superioridade/inferioridade em perdoar uma traição, enquanto ao mesmo tempo demonstram sua inferioridade. Os corpos dóceis fáceis de manipular.

\section{Conclusões}

Conforme fora analisado, o século XIX retratou-se como período de grandes transformações econômicas e sociais com repercussões em outras áreas como da saúde mental, da família e dos costumes. No Brasil, com o fim do Império e o advento da República brasileira anunciou-se o começo de um tempo marcado pelo redimensionamento das políticas de controle social, com a rigidez e parâmetros próprios dos ideais burgueses definidores da família, da nova ordem nas cidades e do papel da mulher dentro desse contexto.

A teoria de Foucault sobre o uso do saber como forma de controle e direcionamento social contribuiu para o entendimento da estrutura da sociedade moderna construída a partir do século XVIII, na qual a mulher, como objeto de controle do ideal da família burguesa, fora restrita ao âmbito doméstico e seu comportamento passou a ser considerado normal a partir de sua sujeição às regras impostas pelo sistema de controle sobre ela.

Dessa forma, o conceito de loucura feminina foi diagnosticado e incorporado na sociedade através de saberes que caracterizavam o que era normal ou não. A maneira de justificar a construção dos sintomas de loucura era explicitamente o corpo feminino e seus movimentos biológicos, que eram desconhecidos, mas julgava-se saber o suficiente para transformar mulheres e pessoas indesejadas na sociedade em loucas.

Da análise da obra História das mulheres no Brasil, organizado por Mary Del Priore, chegou-se à conclusão que, quando o comportamento de uma cidadã não preenchia os requisitos determinantes do padrão exigido na sociedade estruturada a partir dos conceitos burgueses e patriarcais do século XIX, a mulher transformava-se num ser moral e socialmente perigoso, devendo ser submetida a um conjunto de normas extremamente rígidas que assegurassem o cumprimento do seu papel social de esposa e mãe, garantindo a vitória do bem sobre o mal.

Todas essas considerações levaram a construção da especificidade da mulher diante da loucura, o foco do diagnóstico voltava-se para a esfera da sua natureza e sexualidade. O homem era visto como portador de desvios relativos aos papéis sociais, tais como o de trabalhador, o de provedor etc., ou seja, os distúrbios mentais estariam relacionados ao desempenho desses papéis ou à recusa de incorporá-los. Para a mulher, sua fisiologia estaria ligada diretamente a 
predisposição à doença mental.

Foi ao longo da história que a mulher foi se tornando mulher, algumas aceitaram a identidade do que é ser mulher e as assumiram, outras contestaram e discutem até hoje essa formação patriarcal. Sabemos que ainda falta muito, mas que as discussões sobre o papel feminino na sociedade são importantes, principalmente ao que se refere a educação, pois é a partir da educação que as ideologias e conhecimentos são reproduzidos.

Sendo assim, ao passo que a educação vem desmistificando essa identidade naturalizada do que é ser mulher, ela vem também emancipando e abrindo novos espaços a todas as mulheres. Parafraseando Simone de Beauvoir "ninguém nasce mulher: torna-se mulher" isso vem de encontro com o que foi dito até o momento, ou seja, existe um modelo, um padrão, ou um saber de como e o que é ser mulher, e apesar da mudança de século, estes saberes estão tão explícitos nos discursos sociais e culturais que é preciso uma luta diária pelos direitos, pela igualdade, é preciso demonstrar mais uma vez a tal maturidade que nos foi construída para ir aos poucos conquistando os espaços que sempre foi nosso, mas que sempre foi negado.

\section{Referências}

BEAUVOIR, Simone. O segundo sexo: Fatos e Mitos. Trad.: Difusão Européia Do Livro. $4^{\mathrm{a}}$ ed. Brasil. 1980.

D'Incao, Maria Ângela. História das mulheres no Brasil. Mary Del Priore (org.); Carla Bassanezi (coord. de textos). 7. ed. - São Paulo: Contexto, 2004.

EMMERICK, Rulian. Corpo e Poder: um olhar sobre o aborto à luz dos direitos humanos e da democracia. Rio de Janeiro: PUC, 2007. Dissertação de Mestrado apresentada na PUC-Rio, 2007. Disponível em: www.maxwell.vrac.puc-rio.br/10063/10063_1.PDF Acesso em 22 de mai 2018.

ENGEL, Magali. Psiquiatria e feminilidade. IN: PRIORE, Mary Del (org). História das Mulheres no Brasil. $3^{\mathrm{a}}$ ed. São Paulo: Contexto, 2000.

FOUCAULT, Michel. História da Loucura. São Paulo: Perspectiva, 2000.

FOUCAULT, Michel. História da sexualidade II: o uso dos prazeres. Rio de Janeiro: Graal. 1984.

FOUCAULT, Michel. História da sexualidade I: A vontade de saber, tradução de Maria Thereza da Costa Albuquerque e J. A. Guilhon Albuquerque. Rio de Janeiro, Edições Graal, 1988.

FOUCAULT, Michel. Em defesa da sociedade: Curso no Collège de France (1975-1976), (trad. De Maria Ermantina Galvão). São Paulo: Martins Fontes, 2000.

PRIORE, Mary Del; BASSANEZI, Carla. História das mulheres no Brasil. 7. ed. - São Paulo: Contexto, 2004.

SAFFIOTI, Heleieth. Gênero, Patriarcado e Violência. São Paulo: Perseu Abramo, 2004.

SANTOS, Cecília MacDowell; IZUMINO, Wânia Pasinato. Violência contra as Mulheres e Violência de Gênero Notas sobre Estudos Feministas no Brasil. Disponível em: http://www. nevusp.org/downloads/down083.pdf. Acesso em12 mai. 2017. 
SCOTT, Joan W. O enigma da igualdade. Revista de Estudos Feministas. Vol.13. n. 1. Florianópolis: UFSC, jan./abr. 2005.

SOIHET, Rachel. História das mulheres no Brasil. Mary Del Priore (org.); Carla Bassanezi (coord. de textos). 7. ed. - São Paulo: Contexto, 2004.

SOIHET, Rachel. \& PEDRO, Joana M. A emergência da pesquisa da História das Mulheres e das Relações de Gênero. In: Revista Brasileira de História. São Paulo, v.27, 2007.

ZIMMERMANN, Tânia Regina. Violência e Gênero: em notícias no Oeste Paranaense (1960 1990). Jndiaí: Paço Editorial, 2012. 